\title{
Comparison of the Growth of Northern Shrimp (Pandalus borealis) from Four Regions of the Northwest Atlantic
}

\author{
D. G. Parsons, V. L. Mercer and P. J. Veitch \\ Department of Fisheries and Oceans, Science Branch \\ Northwest Atlantic Fisheries Centre, P. O. Box 5667, St. John's, Newfoundland, Canada A1C 5X1
}

\begin{abstract}
Modal analyses of carapace length frequencies and interpretation of biological data for the northern shrimp (Pandalus borealis) indicate variation in both age at sex change and growth rate for some Northwest Atlantic populations. The first female age (the species is protendrous) varied from 6 in the southernmost area to 7 and possibly 8 in more northerly areas. The observed differences could not be related to differences in environmental temperature. Overlapping of modes in the length frequency data was severe in many cases, possibly obscuring an additional mode (age group) in the Davis Strait data. The assumption that sex change occurs at a specific age and the choice of appropriate models and statistical analyses to describe growth require further study.
\end{abstract}

\section{Introduction}

In 1981, the Northwest Atlantic Fisheries Organization (NAFO) convened an ageing workshop on northern shrimp (Pandalus borealis) to address numerous problems encountered in growth studies. The report of that workshop (Fréchette and Parsons, 1983) summarized the results achieved and provided guidelines for age interpretation from length frequency data. Since then, research on shrimp by the Science Branch, Department of Fisheries and Oceans, Canada, Newfoundland Region, has focused on age and growth in various areas of the Northwest Atlantic where commercial fisheries occur. Comparing growth rates from various areas within its range is not only necessary from a purely biological standpoint, but also has important implications for fisheries management in relation to potential yields and harvesting strategies.

Growth interpretation in $P$. borealis (which we shall hereafter refer to as shrimp) is based on the assumption that modes occurring in length frequency distributions represent year-classes. This assumption is tenuous because, frequently, modes extensively overlap and more than one age group may be contained within a single normal component. However, for many stocks in the more northern waters of the Northwest Atlantic, ontogeny appears to be synchronous within year-classes and sex change is likely to occur at a specific age. Thus, it is felt that separation of modes in the length distributions, for male shrimp at least, is an acceptable method of estimating age composition.

The early descriptions of shrimp growth followed Peterson's (1891) method which traced the displace- ment of various size groups over time (Berkeley, 1930; Hjort and Ruud, 1938; Allen, 1959; Haynes and Wigley, 1969). More recently, age composition of samples has been determined by modal analysis of distribution mixtures using both graphical (e.g. Cassie, 1950, 1954; Tanaka, 1962) and analytical (e.g. Abramson, 1971; Macdonald and Pitcher, 1979) methods. A detailed description of growth for populations in the Barents Sea based on modal analysis was given by Teigsmark (1983). Parsons et al. (1986) combined studies on larval growth, observations on shrimp sizes in stomach contents of cod (Gadus morhua) and modal analysis of length frequencies from survey data to determine age and growth in an area off northeastern Newfoundland and southern Labrador. Both those recent studies employed analytical methods of modal separation.

Attempts at ageing, generally, have not considered in detail the moulting frequency involved with increases in size. Although growth-per-moult has been studied extensively for larval and early juvenile stages (Stickney and Perkins, 1977; Haynes, 1979; Wienberg, 1982; Nunes, 1984), virtually no data are yet available on the number of moults which adults undergo annually. Models chosen to describe growth in this species have consequently ignored the step-wise increase in the size of animals and defaulted, primarily, to the von Bertalanffy (1938) growth equation (Fréchette and Parsons, 1983).

In this paper, sampling data from four areas of the Northwest Atlantic are analyzed. It was observed that, in three of the areas, the mean sizes of females and maximum lengths of males were similar. The fourth, however, showed obviously larger females and males. To elucidate the differences, age and growth are inter- 
preted for each area and the results are compared between areas and with previous findings reported in literature. The problems of statistical comparison and the choice of an appropriate growth model are also discussed.

\section{Methods and Materials}

Random samples of shrimp, collected during research surveys conducted by the Department of Fisheries and Oceans in the Northwest Atlantic from 1978 to 1987 , were preserved in 10\% formalin for subsequent observations in the laboratory. Although a number of different research vessels were used, the sampling gear, a Sputnik 1600 shrimp trawl, remained constant. Mesh size (stretched) ranged from about 80 $\mathrm{mm}$ in the wings to $42 \mathrm{~mm}$ in the codend and the last $6 \mathrm{~m}$ of codend were lined with $13 \mathrm{~mm}$ mesh to reduce the loss of smaller animals. The trawl was towed routinely at approximately $5.6 \mathrm{~km} / \mathrm{hr}$ for $0.5 \mathrm{hr}$.

Most samples were obtained in July except for 1985 and 1986 in St. Anthony Basin and Cartwright Channel (August), and 1981 in Davis Strait (September). Samples from Davis Strait in 1980, 1981 and 1984 were obtained from commercial vessels which also used gear with a codend mesh size of about $40 \mathrm{~mm}$ but without a liner. Samples from the same year were pooled by area after initial examination of data revealed no substantial differences in the overall length distributions (i.e. similar size range, similar modes). Data were analyzed for four sampling areas with general locations as shown in Fig. 1:

1. St. Anthony Basin - Division 3K (five samples, 1981-86)

2. Cartwright Channel - Division 2J (eight samples, 1980-87)

3. Hopedale Channel - Division $2 \mathrm{H}$ (seven samples, 1981-87)

4. Davis Strait - Subareas $0+1$ (six samples, 1978-86)

Oblique carapace length (cl) (Rasmussen, 1953) was measured to the nearest $0.1 \mathrm{~mm}$ using Vernier calipers and subsequently combined into $0.5 \mathrm{~mm}$ intervals (Frechette and Parsons, 1983), the left bound being the reference for the interval. Shrimp were separated into male and female components based on the characteristics of the endopod of the first pleopod (Rasumssen, 1953). Females were further separated into primiparous (first time spawners) and multiparous (spawned previously) groups based on the condition of the sternal spines (McCrary, 1971).

Model analyses (Macdonald and Pitcher, 1979) were performed on male length distributions only, to obtain estimates of the mean for each normal component. The number of normal components in each distribution was determined by visual inspection and the

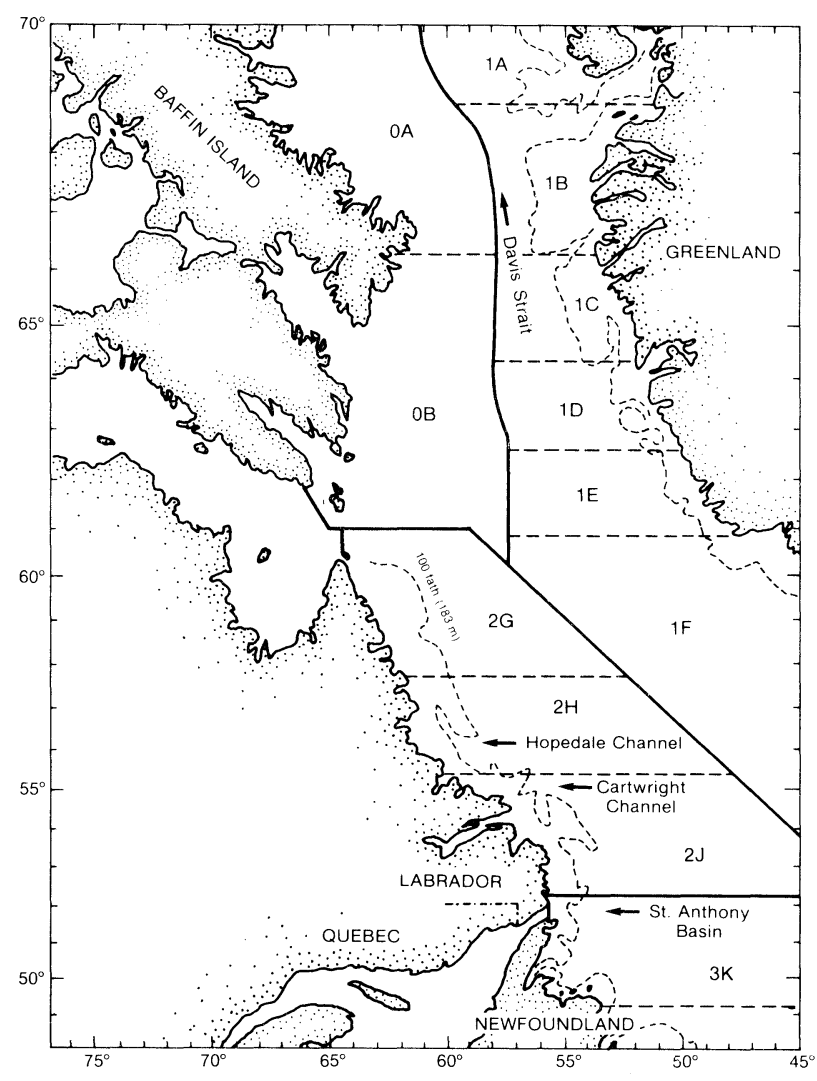

Fig. 1. Areas in the Northwest Atlantic from which samples of shrimp were compared for differences in growth.

input standard deviations were estimated by penciland-paper separation of the assumed components. The output from the analysis was largely dependent on the starting values, and in that sense the method suffered from lack of objectivity, especially in the assumption of the number of components. Mean sizes of primiparous and multiparous females were calculated directly from sampling data. In doing so, it was assumed that primiparous females constituted a separate age-class and that multiparous females comprised a number of older age-classes. The validity of these assumptions is discussed in more detail below. Ageing of various components, based on findings of Parsons et al. (1986), assumed that growth rates of shrimp larvae were similar throughout the sampling area.

To facilitate the interpretation of age composition of samples, preliminary modal analyses were conducted by area for each year, separately. The results, in terms of mean size-at-age, were tabulated and reviewed for consistency between years. Then, a final analysis was conducted by area for all years combined. It was felt that this method provided an appropriate description of average growth within each area by inherently averaging year-to-year variability in lengthat-age as well as variation in the growth rates of the different cohorts. Comparison of the growth rates by area was descriptive only, as there appeared to be no suitable statistical procedure for analysis of such data. 


\section{Results}

Five years of sampling data from the St. Anthony Basin revealed four modes of male shrimp that were interpreted as year-classes (Fig. 2, Table 1A). Although
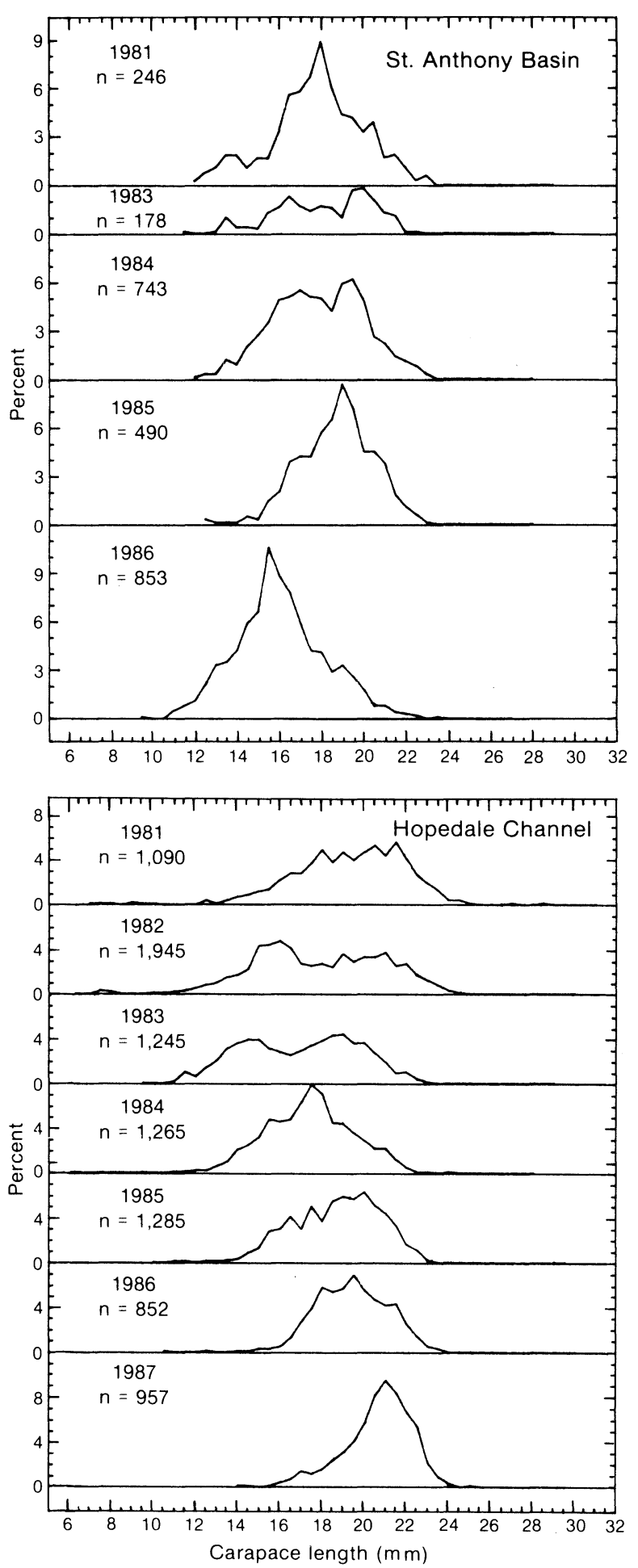

three or four modes were evident in most years, substantial overlap in many cases made it difficult to estimate the parameters of some components. Only the means estimated with some confidence are given in Table 1 (i.e. those with large standard errors were not
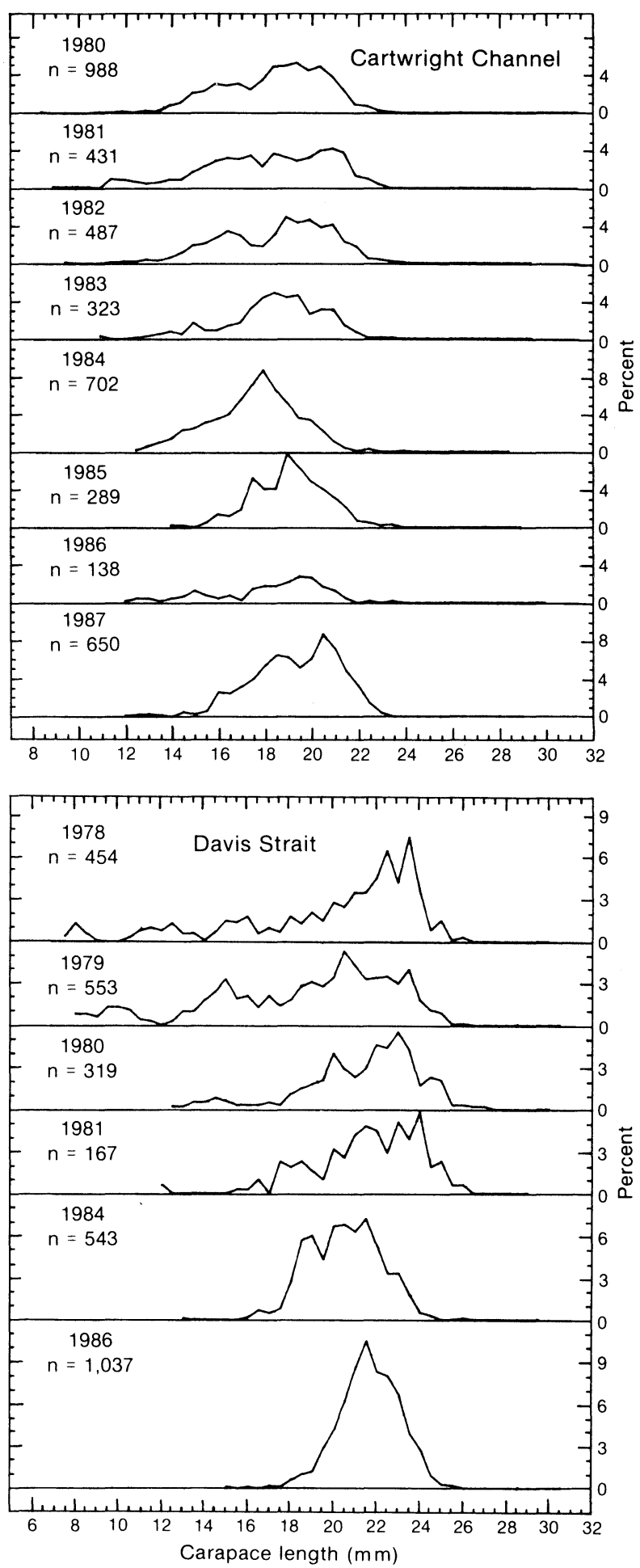

Fig. 2. Length distributions of male shrimp from samples taken in four areas of the Northwest Atlantic, 1978-87. 
TABLE 1. Mean carapace lengths $(\mathrm{mm})$ estimated by modal analysis for male shrimp and by direct calculation for primiparous and multiparous females in four areas of the Northwest Atlantic.

\begin{tabular}{|c|c|c|c|c|c|c|c|c|}
\hline \multirow[b]{2}{*}{ Year } & \multicolumn{6}{|c|}{ Males } & \multicolumn{2}{|c|}{ Females } \\
\hline & 1 & 11 & III & IV & V & VI & Primi. & Multi. \\
\hline \multicolumn{9}{|c|}{ A. St. Anthony Basin } \\
\hline 1981 & 13.6 & - & - & 20.7 & - & - & 22.9 & 24.2 \\
\hline 1983 & 13.7 & 16.3 & 18.1 & 20.2 & - & - & 22.6 & 24.8 \\
\hline 1984 & - & 16.4 & - & 19.5 & - & - & 22.7 & 23.9 \\
\hline 1985 & - & 16.8 & 18.9 & 20.5 & - & - & $21.9^{\mathrm{a}}$ & 23.9 \\
\hline 1986 & - & 16.3 & - & - & - & - & $22.4^{\mathrm{a}}$ & 23.6 \\
\hline Average & 13.7 & 16.5 & 18.5 & 20.2 & - & - & 22.7 & 24.1 \\
\hline \multicolumn{9}{|c|}{ B. Cartwright Channel } \\
\hline 1980 & - & 15.6 & - & 19.3 & 20.9 & - & 22.9 & 24.6 \\
\hline 1981 & 12.3 & - & - & 18.8 & 21.0 & - & 23.3 & 25.1 \\
\hline 1982 & - & - & - & 19.3 & 20.9 & - & 23.2 & 24.6 \\
\hline 1983 & - & 15.0 & - & - & 20.6 & - & 22.6 & 25.3 \\
\hline 1984 & - & 15.4 & 18.0 & 20.1 & - & - & 1.9 & 24.1 \\
\hline 1985 & - & - & 17.7 & 19.4 & 21.0 & - & 2.1 & 24.3 \\
\hline 1986 & 12.6 & 15.2 & 17.9 & 19.8 & - & - & $20.7^{\mathrm{a}}$ & 24.0 \\
\hline 1987 & - & - & - & - & 20.7 & - & 23.9 & 25.4 \\
\hline Average & 12.5 & 15.3 & 17.9 & 19.5 & 20.9 & - & 22.8 & 24.7 \\
\hline \multicolumn{9}{|c|}{ C. Hopedale Channel } \\
\hline 1981 & - & - & - & - & - & - & 23.9 & 24.7 \\
\hline 1982 & 13.3 & 15.9 & - & 19.2 & 21.5 & - & 4.3 & 25.3 \\
\hline 1983 & - & - & 18.0 & 19.6 & - & - & 22.8 & 25.0 \\
\hline 1984 & - & 15.8 & 17.7 & 19.4 & 20.8 & - & 22.5 & 24.3 \\
\hline 1985 & - & - & - & 19.3 & 21.0 & - & 22.7 & 24.0 \\
\hline 1986 & - & - & 18.0 & 19.6 & 21.3 & - & 23.5 & 24.5 \\
\hline 1987 & - & - & 17.2 & 18.9 & 21.2 & - & 23.9 & 25.1 \\
\hline Average & 13.3 & 15.9 & 17.7 & 19.3 & 21.2 & - & 23.4 & 24.7 \\
\hline \multicolumn{9}{|c|}{ D. Davis Strait } \\
\hline 1978 & 8.1 & 12.1 & 15.5 & 18.6 & 20.6 & 22.9 & 25.4 & 26.5 \\
\hline 1979 & 9.6 & - & 15.0 & 18.8 & 20.6 & 22.8 & 25.0 & 26.4 \\
\hline 1980 & - & - & 14.7 & - & 20.1 & 22.8 & 25.8 & 26.5 \\
\hline 1981 & - & - & - & 18.1 & 21.3 & 23.8 & 25.2 & 26.4 \\
\hline 1984 & - & - & - & 18.6 & 20.5 & 22.2 & $24.3^{\mathrm{a}}$ & 25.7 \\
\hline 1986 & - & - & - & 18.7 & 21.0 & 22.5 & 24.9 & 25.6 \\
\hline Average & 8.9 & 12.1 & 15.1 & 18.6 & 20.7 & 22.8 & 25.3 & 26.2 \\
\hline
\end{tabular}

a Sample size too small for inclusion in average.

used). For 1986, average length was used for males, as well as primiparous and multiparous females, there being only one clear mode in the length frequency. Estimated mean lengths for each presumed year-class were similar, especially for the younger ages and there was no overlap in the range of means with adjacent year-classes. Female groups were well separated by over $1 \mathrm{~mm} \mathrm{cl}$ and clearly separated from the largest group of males. These preliminary analyses were intended to reveal consistencies in the data between years in terms of the number of age groups present in the samples. Although the final "averages" were not clearly represented in all the samples, there was evidence to suggest that they occurred with some regularity from year to year.
Samples from Cartwright Channel from 1980 to 1987 provided evidence of five modal groups of males, compared to four in the St. Anthony Basin. The means for five components, however, could not be estimated with confidence from any sample in any single year (Table 1B). Individual length frequencies in Fig. 2 show that modes were substantially overlapped, especially between the second and third and the fourth and fifth components. In samples where a fifth mode was not obvious (1984 and 1986), the mean size of the fourth tended to be substantially larger. Mean sizes of other normal components could similarly have been either over or underestimated, depending on whether or not the overlap had been resolved. An independent review of length frequency data covering a wide range of depths supported the presence of five "average" size groups evident here (Parsons, unpublished data). Despite these problems, the range of the mean lengths did not overlap the adjacent year-class estimates. Primiparous females were about $2 \mathrm{~mm} \mathrm{cl}$ larger than the largest male component in most cases and the multiparous females were larger than the primiparous group.

Five modes were also evident in samples from the Hopedale Channel (Fig. 2, Table 1C). As many as four were estimated in samples from two years, but in one case (1981) no clear modes were identifiable. The smallest modal size was estimated at $13 \mathrm{~mm}$, however, this was in only one sample (1982). As in Cartwright Channel, modes were overlapped, especially the second and third and the third and fourth components. The "average" lengths were similar to those obtained for Cartwright Channel and the associated ranges did not overlap with those of the adjacent year-classes. The difference between average lengths of the primiparous and multiparous female groups was less than $2 \mathrm{~mm}$ for all years except 1983 and primiparous females were substantially larger than the largest male component.

Six modes of males were identified in Davis Strait (Fig. 2, Table 1D). All six were apparent in the 1978 sample and five in 1979, while the smallest three modes were not clearly represented in the last 3 years. The extra mode (about $9 \mathrm{~mm} \mathrm{cl}$ ) observed in this area represented an age class which appeared to be one year younger than the smallest mode present in the other areas. The mean lengths of the three largest male groups were substantially greater than the corresponding means in the more southerly areas, as were the mean sizes of the two female groups.

Based on these preliminary observations and analyses, estimates of the average lengths at assumed ages and the number of male components were used in a final modal analysis by area for all years combined (Fig. 3 ). For primiparous and multiparous females, the average lengths were calculated from the pooled data. 

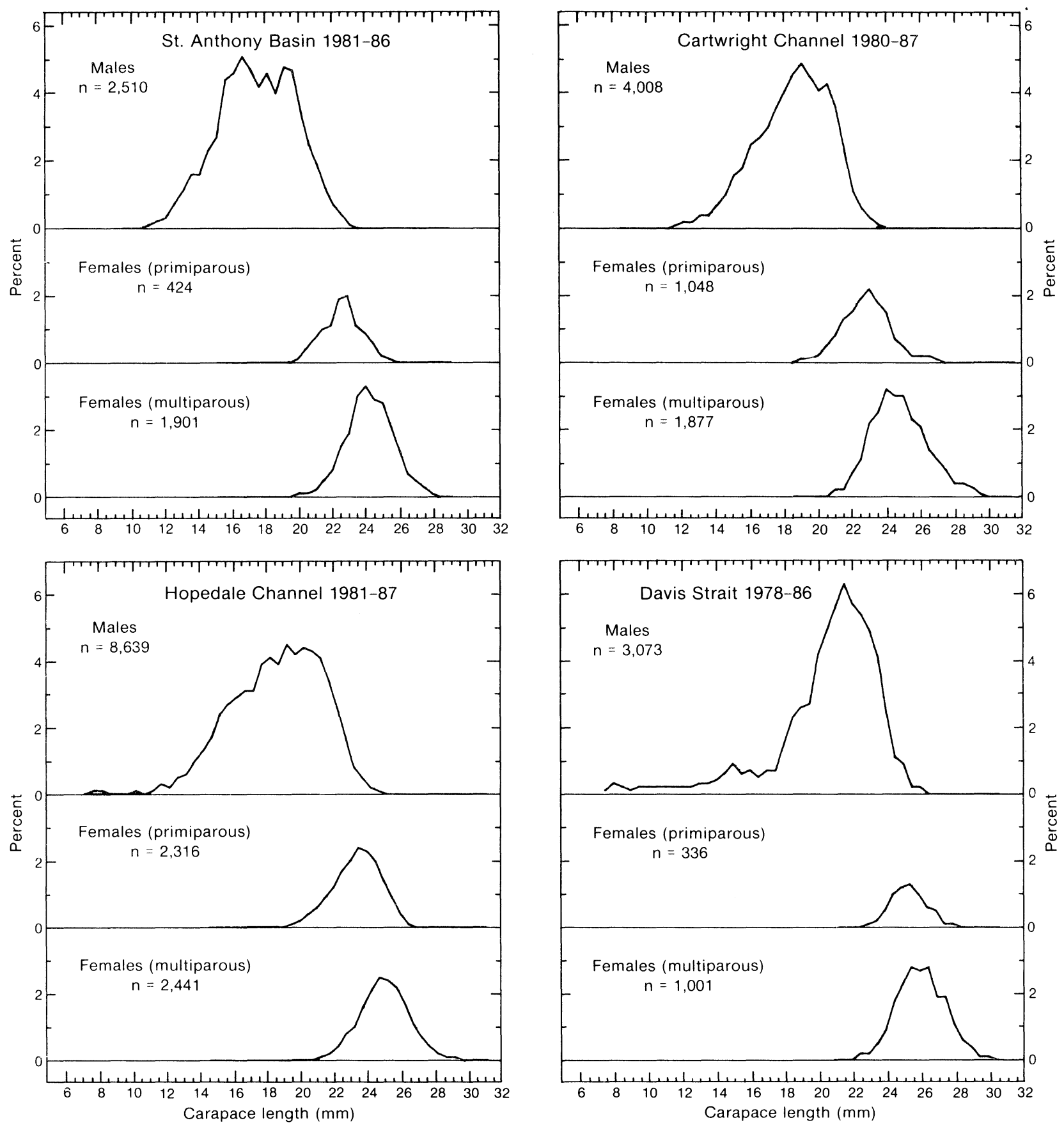

Fig. 3. Pooled length distributions of male and female (primiparous, multiparous) shrimp taken in four areas of the Northwest Atlantic.

Results of the modal analyses are summarized in Table 2. For St. Anthony Basin, the procedure did not run freely (i.e. constraints were needed for parameters) but acceptable standard errors were obtained by holding the standard deviation of the largest component fixed at a previously estimated value of 1.20. Assuming four modes and mean lengths as estimated in the preliminary analyses, the expected distribution was not significantly different from the observed (chi-square = 14.3, $P=0.51$ ) (Fig. 4). The extreme overlap of pooled
Cartwright Channel data was very difficult to resolve. The "best" run was obtained by holding the proportions and standard deviations of the third and fourth modes fixed at previously estimated values. Under these numerous assumptions, the expected distribution was not significantly different from the observed (chisquare $=13.8, P=0.61$ ). Combined data for Hopedale Channel provided more information on the left side of the length frequency distribution and another size group with an average length of $7.7 \mathrm{~mm} \mathrm{cl}$ became 
TABLE 2. Results of Macdonald and Pitcher (1979) modal analyses by area, all years combined.

\begin{tabular}{|c|c|c|c|c|c|c|}
\hline Mode & $\%$ & $\begin{array}{l}\text { Standard } \\
\text { error }\end{array}$ & $\begin{array}{c}\text { Mean } \\
\text { carapace } \\
\text { length }\end{array}$ & $\begin{array}{l}\text { Standard } \\
\text { error }\end{array}$ & $\begin{array}{l}\text { Standard } \\
\text { deviation }\end{array}$ & $\begin{array}{c}\text { Standard } \\
\text { error }\end{array}$ \\
\hline \multicolumn{7}{|c|}{ St. Anthony Basin } \\
\hline 1 & 11.0 & $(7.6)$ & 13.7 & $(0.8)$ & 1.13 & $(0.27)$ \\
\hline 11 & 47.1 & $(17.0)$ & 16.4 & $(0.2)$ & 1.18 & $(0.36)$ \\
\hline III & 22.3 & $(16.6)$ & 19.0 & $(0.3)$ & 0.89 & $(0.29)$ \\
\hline IV & 20.0 & $(8.7)$ & 20.2 & $(0.3)$ & 1.20 & $\left({ }^{*}\right)$ \\
\hline \multicolumn{7}{|c|}{ Cartwright Channel } \\
\hline 1 & 1.8 & $(0.9)$ & 12.6 & $(0.4)$ & 0.82 & $(0.22)$ \\
\hline II & 20.3 & $(7.6)$ & 15.8 & $(0.4)$ & 1.19 & $(0.29)$ \\
\hline III & 35.6 & $\left({ }^{*}\right)$ & 18.3 & $(0.4)$ & 1.19 & $\left({ }^{*}\right)$ \\
\hline IV & 17.0 & $\left({ }^{*}\right)$ & 19.4 & $(0.4)$ & 1.17 & $\left({ }^{*}\right)$ \\
\hline v & 25.3 & (6.9) & 20.7 & $(0.2)$ & 1.01 & $(0.08)$ \\
\hline \multicolumn{7}{|c|}{ Hopedale Channel } \\
\hline 1 & 6.5 & (3.1) & 13.6 & $(0.6)$ & 1.28 & $(0.22)$ \\
\hline II & 21.4 & (2.0) & 15.7 & $(0.2)$ & 1.08 & $\left({ }^{*}\right)$ \\
\hline III & 16.0 & (6.1) & 17.7 & $(0.3)$ & 0.88 & $\left({ }^{*}\right)$ \\
\hline IV & 27.7 & (5.6) & 19.3 & $(0.7)$ & 1.13 & $\left({ }^{*}\right)$ \\
\hline v & 28.4 & $(1.1)$ & 21.2 & $(0.4)$ & 1.14 & $(0.11)$ \\
\hline \multicolumn{7}{|c|}{ Davis Strait } \\
\hline 1 & 0.6 & $(0.5)$ & 8.1 & $(0.2)$ & 0.21 & $(0.38)$ \\
\hline 11 & 2.2 & $(1.0)$ & 10.2 & $(0.4)$ & 1.36 & $(0.69)$ \\
\hline III & 10.4 & (2.0) & 15.7 & $(0.3)$ & 1.84 & $(0.43)$ \\
\hline IV & 7.2 & (3.9) & 18.6 & $(0.2)$ & 0.52 & $(0.14)$ \\
\hline V & 29.2 & (19.9) & 20.5 & (0.3) & 0.97 & $(0.33)$ \\
\hline VI & 50.4 & (17.3) & 22.5 & $(0.4)$ & 1.23 & $(0.14)$ \\
\hline
\end{tabular}

${ }^{\star}=$ Parameters constrained at previously estimated values.

evident (Fig. 3). Modal analysis of the larger sizes was achieved by holding the standard deviations of the second, third and fourth modes fixed at previously estimated values. However, the overall fit was not as good as in the other two cases (chi-square $=21.8, P=0.19$ ). The analysis for Davis Strait assuming six components and using the means estimated previously ran freely (chi-square $=25.1, P=0.24)$. Five of the six means estimated in the final run were close to the initial starting values but the second mean was about $2 \mathrm{~mm}$ smaller. Yearly data showed that this second component was only obvious in the 1978 sample, therefore, the mean size of $12.1 \mathrm{~mm} \mathrm{cl}$ as estimated from that sample was used.

Ages were assigned for each area assuming the smallest size group at roughly $8 \mathrm{~mm} \mathrm{cl}$ represented 1-year-olds (Parsons et al., 1986). The results, summarized by area (Fig. 5, Table 3), show the apparent differences in growth and maturation. Shrimp in St. Anthony Basin function as males up to age 5 then change sex and function as females for the first time at age 6 , whereas, in the more northern areas, growth rate is slower and sex change occurs between ages 6 and 7 . Growth and maturation appear to be similar in the Cartwright and Hopedale Channels. Although matura- tion in Davis Strait appears similar to that in the Channels, growth rate appears greater and, beyond age 3 , mean length at age is substantially larger. For all areas, annual growth increments progressively decreased during the male phase, increased at sex change and decreased again during the female phase.

\section{Discussion}

It is important to note that the analyses assume that the available sampling data are representative of the population. However, there is considerable variation in shrimp distribution on both temporal and spatial scales which possibly influence the results to some extent. Unfortunately, the data base was not sufficient to address the problem. Length-at-age can vary within area by depth, season and even time of day. It is possible, however, that by taking samples from several years in each area, some of the potential biases might be minimized.

The above results indicate variation in the rates of both growth and maturity for shrimp in the Northwest Atlantic. First spawning as females occurred at age 6 in the St. Anthony Basin and at age 7 in the areas farther 


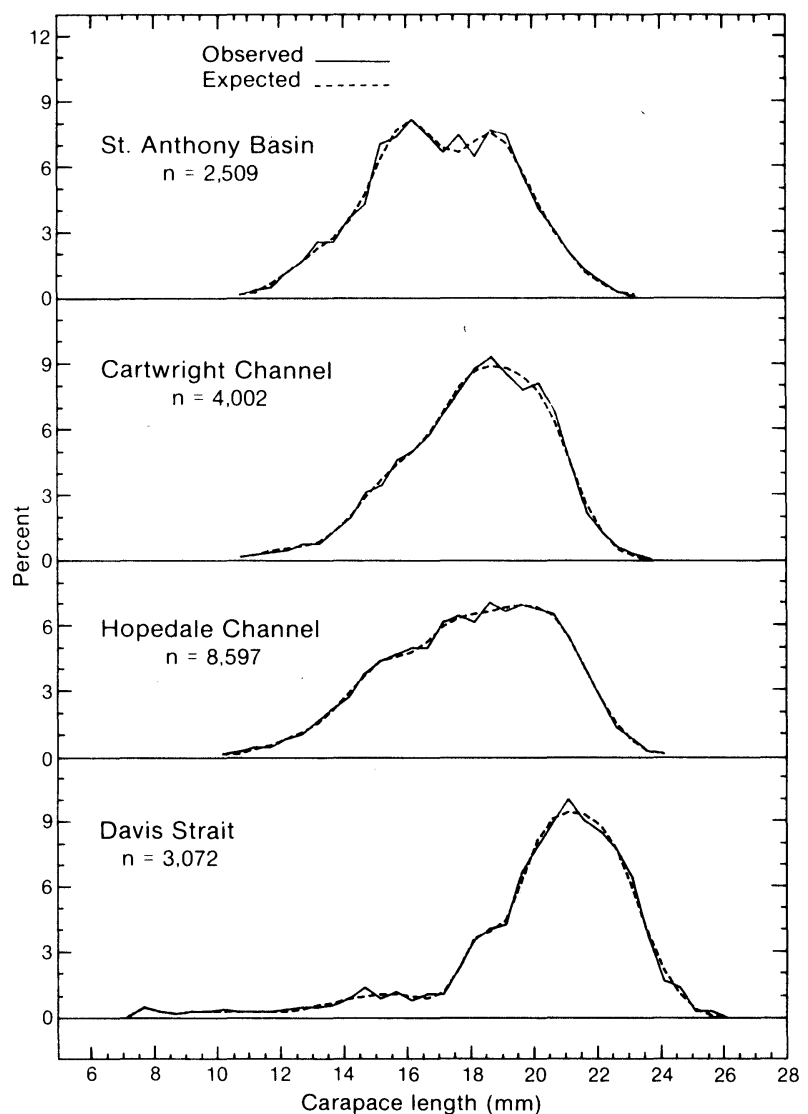

Fig. 4. Observed and expected length distributions of male shrimp from pooled samples taken in four areas of the Northwest Atlantic, 1978-87.

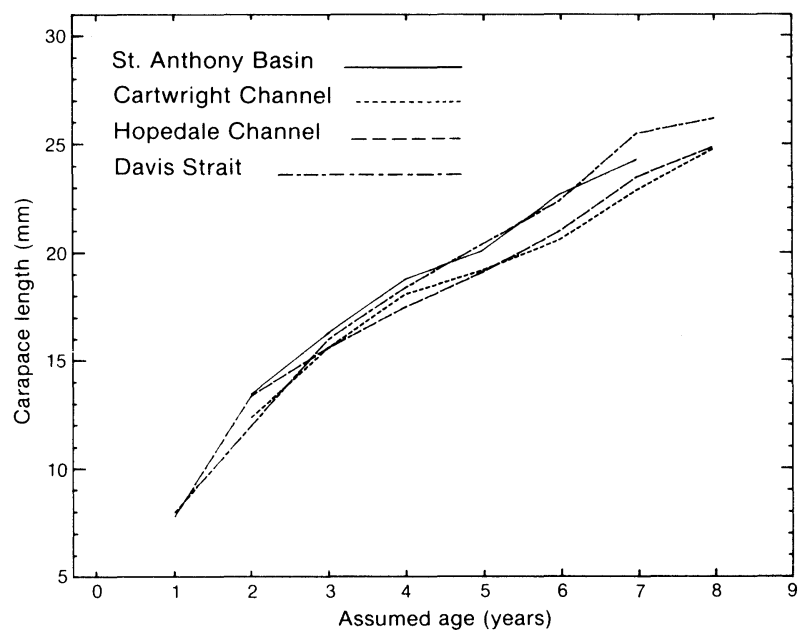

Fig. 5. Mean carapace length $(\mathrm{mm})$ at age by area.

north. Teigsmark (1983) also noted first spawning at age 6 in a Barents Sea population, but thereafter spawning occurred every second year. This differs from the areas studied here in that annual spawning occurs for the majority of females. Parsons et al. (1986) intepreted data collected in 1984 from the St. Anthony
TABLE 3. Mean carapace length $(\mathrm{mm})$ at age by area as determined through modal analysis of males and separation of primiparous and multiparous females by sternal spines (all years combined).

\begin{tabular}{lrrrrrrrrr}
\hline \hline & \multicolumn{8}{c}{ Assumed age (years) } \\
\cline { 2 - 9 } Stock area & 1 & 2 & 3 & 4 & 5 & 6 & $7\left(^{+}\right)$ & $8+$ \\
\hline St. Anthony Basin & & 13.7 & 16.4 & 19.0 & 20.2 & $22.6^{\mathrm{a}}$ & 24.2 & \\
Cartwright Channel & & 12.6 & 15.8 & 18.3 & 19.4 & 20.7 & $22.8^{\mathrm{a}}$ & 24.7 \\
Hopedale Channel & 7.9 & 13.6 & 15.7 & 17.7 & 19.3 & 21.2 & $23.4^{\mathrm{a}}$ & 24.8 \\
Davis Strait & 8.1 & $12.1^{\mathrm{b}}$ & 15.7 & 18.6 & 20.5 & 22.5 & $25.4^{\mathrm{a}}$ & 26.1 \\
\hline
\end{tabular}

a First female group

b From 1978 sample only.

Basin to suggest that first spawning as females occurred at age 5. It now appears that the size groups in that sample (Fig. 2) were severely overlapped and that the number of ages was underestimated. The methodology used here reduces the possibility of misinterpretation by looking for consistency in the occurrence of size groups over time (Macdonald, 1987).

The similarity between observations in the Hopedale and Cartwright Channels might be expected, given that environmental conditions in the two areas are similar. The smaller mean length at several ages in the latter are consistent with the slightly colder water temperatures that have been observed in this Channel (Parsons, 1982). In areas of St. Anthony Basin where shrimp were highly concentrated, temperatures ranged from approximately $2^{\circ}$ to $4^{\circ} \mathrm{C}$, similar to the range found in the channels to the north. The accepted theory is that growth is slower, maturity delayed and longevity increased in colder waters (Allen, 1959; Haynes and Wigley, 1969; Rasmussen, 1969; Butler, 1971), however, the differences observed here between the St. Anthony Basin and areas farther north cannot be explained in terms of temperatures.

Although the range of bottom temperatures $\left(1^{\circ}\right.$ to $4^{\circ} \mathrm{C}$ ) in Davis Strait where shrimp occur (Atkinson et al., 1982) is also similar to that in Hopedale and Cartwright Channels, the mean lengths at age are considerably larger beyond age 3 . It is possible that the modes were sufficiently overlapped to obscure another yearclass. If this were the case, a trend of slower growth and increased longevity with increasing latitude would be more firmly established. Length frequencies for 1979 and 1981 from Davis Strait suggest the possibility that an additional mode exists at roughly $16.5 \mathrm{~mm}$, between the adjacent modes at 15 and $18 \mathrm{~mm}$. Before a definitive statement is made about growth and maturity in this area, more samples from a longer period and covering a larger area must be analyzed.

The results described here for Davis Strait differ greatly from those reported by Horsted and Smidt (1956) for other areas at West Greenland. In previous studies, first spawning for some shrimp stocks in near and inshore areas was thought to occur at age 4 or 5 . In Disko Bay, where the bottom temperatures appeared to be colder than on the adjacent Davis Strait grounds, the 
first female age class was estimated to be 5 years old, compared to age 7 (possibly 8 ) in the offshore areas interpreted in the present study. Similar to ourfindings, Horsted and Smidt (1956) also observed slower rates of development with increasing latitude which could not be associated with changes in temperature.

It was assumed in this study that sex change occurred at a specific age. The analyses showed clear separation of the mean lengths for the oldest male group, primiparous and multiparous females. However, it has been observed that for some populations, two modal length groups of transitionals may exist simultaneously (Rasmussen, 1953; 1969), indicating that sex change may occur within more than one year-class. For certain areas at West Greenland, Horsted and Smidt (1956) observed development in which a fraction of what they interpreted as 4 year olds continued to function as males until age 5 while the remainder changed sex. If this occurs, the mean sizes of the adjacent yearclasses might be underestimated, depending on the proper assignment of age to the first "mode" of primiparous females. Also, the assumption that the multiparous group contains components which are older than the primiparous group then become invalid. More sampling data from all areas are needed to determine whether or not sex change occurs at a specific age.

The comparison of growth between areas presented here is descriptive only. There does not appear to be any conventional statistical procedure to test for similarities using the data from this type of analysis. Misra (1987) provided a program to compare statistically several von Bertalanffy growth curves, but such curves are generally derived from a large number of observations of length-at-age. The data generated from modal analysis do not appear to be suitable for such treatment. Although the von Bertalanffy model has been used in the past to provide a general description of shrimp growth (Fréchette and Parsons, 1983), it precludes the stepwise increments characteristic of crustacean growth and ignores the apparent rapid growth that occurs during the transitional period. Less growth might be expected during this period due to the energy required to change sex but rapid growth of transitionals has been noted previously for this species (Shumway et al., 1985) and probably results from the frequent number of moults required to complete the change. The present study provides a descriptive comparison of growth and maturation patterns of the northern shrimp. It also demonstrates the need to develop appropriate models and statistical analyses so that interpretations such as those made in the study can be supported or rejected within the limitations of the data.

\section{References}

ABRAMSON, N. J. 1971. Computer programs for fish stock assessment. FAO Fish. Tech. Pap., No. 101.
ALLEN, J. A. 1959. On the biology of Pandalus borealis Krøyer, with reference to a population off the Northumberland coast. J. Mar. Biol. Assoc. U.K., 38: 189-220.

ATKINSON, D. B., W. R. BOWERING, D. G. PARSONS, Sv. Aa. HORSTED, and J. P. MINET. 1982. A review of the biology and fisheries for roundnose grenadier, Greenland halibut and northern shrimp in Davis Strait. NAFO Sci. Coun. Studies, 3: 7-27.

BERKELEY, A. A. 1930. The post-embryonic development of the common pandalids of British Columbia. Contrib. Can. Biol. Fish., N.S., 6: 79-163.

BERTALANFFY, L. von. 1938. A quantitative theory of organic growth. Hum. Biol., 10(2): 181-213.

BUTLER, T. H. 1971. A review of the biology of the pink shrimp, Pandalus borealis Krøyer 1838. Canadian Fish. Rep., 17: 17-24.

CASSIE, R. M. 1950. The analysis of polymodal frequency distributions by the probability paper method. N.Z. Sci. Rev., 8: 89-91.

1954. Some uses of probability paper in the analysis of size frequency distributions. Aust. J. Mar. Freshwat. Res., 5: 513-522.

FRÉCHETTE, J., and D. G. PARSONS. 1983. Report of shrimp ageing workshop held at Ste. Foy, Quebec, in May and at Dartmouth, Nova Scotia, in November 1981. NAFO Sci. Coun. Studies, 6: 79-100.

HAYNES, E. 1979. Description of larvae of the northern shrimp, Pandalus borealis, reared in situ in Kachemak Bay, Alaska. Fish. Bull. U.S., 77: 157-173.

HAYNES, E. B., and R. L. WIGLEY. 1969. Biology of the northern shrimp, Pandalus borealis, in the Gulf of Maine. Trans. Amer. Fish. Soc., 98: 60-76.

HJORT, J., and J. T. RUUD. 1938. Deep sea prawn fisheries and their problems. Hvalråd. Skr., 17: 1-144.

HORSTED, Sv. Aa., and E. SMIDT. 1956. The deep sea prawn (Pandalus borealis Kr.) in Greenland waters. Medd. Dan. Fisk.-Havunders., N.S., 1(11): 118 p.

MACDONALD, P. D. M. 1987. Analysis of length-frequency distributions. p. 371-384. In: Age and growth of fish. R. E. Summerfelt and G. E. Hall (eds.). lowa State Univ. Press, Ames, lowa.

MACDONALD, P.D. M., and T. J. PITCHER. 1979. Age-groups from size-frequency data: $A$ versatile and efficient method of analyzing distribution mixtures. J. Fish. Res. Board Can., 36: 987-1011.

MCCRARY, J. A. 1971. Sternal spines as a characteristic for differentiating between females of some Pandalidae. $J$. Fish. Res. Board Can., 28: 98-100.

MISRA, R. K. 1987. A program to compare statistically the generalized von Bertalanffy growth curves and their parameters. Can. Tech. Rep. Fish. Aquat. Sci., 1439: 89 p.

NUNES, P. 1984. Reproductive and larval biology of northern shrimp Pandalus borealis (Krøyer) in relation to temperature. Ph.D. Thesis, Univ. of Alaska, Fairbanks, $195 \mathrm{p}$

PARSONS, D. G. 1982. Biological characteristics of northern shrimp (Pandalus borealis Krøyer) in areas off Labrador. M.Sci. Thesis, Memorial Univ., St. John's, Newfoundland, Canada, $123 \mathrm{p}$.

PARSONS, D. G., G. R. LILLY, and G. J. CHAPUT. 1986. Age and growth of northern shrimp Pandalus borealis off northeastern Newfoundland and southern Labrador. Trans. Amer. Fish. Soc., 115: 872-881.

PETERSON, C. G. J. 1891. Eine methode zur bestimmug des alters und wucks der fische. Mitt. Dtsch. Seefisch. Ver., 11: 226-235. 
RASMUSSEN, B. 1953. On the geographical variation in growth and sexual development of the deep sea prawn (Pandalus borealis $\mathrm{Kr}$.). Norweg. Fish. and Mar. Invest. Rep., 10(3): 1-160.

1969. Variations in protendric hermaphroditism of Pandalus borealis. FAO Fish. Rep., 57: 1101-1106.

SHUMWAY, S. E., H. C. PERKINS, D. F. SCHICK, and A. P. STICKNEY. 1985. Synopsis of biological data on the pink shrimp, Pandalus borealis Krøyer, 1838. NOAA Tech. Rep., NMFS 30, $57 \mathrm{p}$.

STICKNEY, A. P., and H. C. PERKINS. 1977. Environmental physiology of commercial shrimp (Pandalus borealis). Project 3-202-R Completion Report, February 1 to Janu- ary 31, 1977. Dep. Mar. Resour., W. Boothbay Harbor, Maine, USA, $78 \mathrm{p}$.

TANAKA, S. 1962. A method of analyzing polymodal frequency distributions and its application to the length distribution of the porgy, Taius tumifrons. J. Fish. Res. Board Can., 19: 1143-1159.

TEIGSMARK, G. 1983. Populations of the deep-sea shrimp (Pandalus borealis Krøyer) in the Barents Sea. Fiskeridir. Skr. (Havunders.) 17: 377-430.

WIENBERG, R. 1982. Studies on the influence of temperature, salinity, light, and feeding rate on laboratory reared larvae of deep sea shrimp, Pandalus borealis Krфyer 1838. Ber. Dtsch. Wiss. Komm. Meeresforsch., 29: 136-153. 
